\title{
Children's Advertising Literacy for New Advertising Formats: The Mediating Impact of Advertising Literacy on the (Un)Intended Effects of Advergames and Advertising Funded Programs.
}

\author{
Hudders, Liselot; Cauberghe, Veroline; Panic, Katarina; De Vos, Wendy
}

\section{Introduction}

To be able to stand out in today's crowded advertising environment and to reach children more effectively, advertisers are adopting new advertising venues, such as advergames, product placements, branded websites, or mobile applications (Calvert, 2008; Moore, 2004). Three important characteristics of these new advertising formats are a longer exposure time to commercial content, the integration of commercial content into the media content and the interactive engagement of the user with the commercial content (Rozendaal et al., 2012). In the current paper, we will investigate children's advertising literacy level, purchase requests and materialism level after exposure to either an advertiser funded program (AFP, defined as a program produced by an advertiser) or an advergame (defined as a simple game specially designed by an advertiser). These ad formats differ in their degree of interactivity, since an advergame is highly interactive, whereas an AFP is not. In both formats the brand is integrated in the media format. In addition, the current study will investigate whether an advertising literacy training session may improve children's advertising literacy and thereby attenuating both intended (purchase requests) and unintended advertising effects (level of materialism).

Various studies have already shown that new advertising formats can generate more positive brand attitudes and purchase requests compared to traditional formats, especially with children. As such, a study by Panic et al. (2013) shows that an advergame generates more positive brand attitudes with children compared to a traditional television commercial. However, new advertising formats may also increase the unintended effects on children, such as lower well-being or more materialistic values. This can be explained by the fact that children do not fully understand the persuasive character of these formats while they love them, leading to less irritation and resistance towards such advertisements. In other words, children appear to have lower levels of cognitive and affective advertising literacy for such new formats (defined as the skills of 
analyzing and evaluating persuasive messages across a variety of contexts and media; Rozendaal et al., 2012). This limited advertising literacy may lead to a higher impact of these formats, both in terms of intended (i.e. purchase requests) and unintended effects (i.e. materialistic values).

Previous studies on children's advertising literacy level for new advertising formats mainly focused on traditional TV ads and advergames. However, these studies did not investigate the impact of the level of interactivity with the commercial content on advertising literacy and (un)intended effects of advertising. Hence, in the current study, we will compare children's advertising literacy level for an advergame versus an AFP. While both formats are characterized by the embedding of commercial content into media content, the AFP does not interactively engage the users with this content whereas an advergame does. In addition, we will investigate how these two formats affect children's purchase requests for the brands endorsed in these formats (measured by their pester power, cf. the intended effect) and their materialism level (cf. the unintended effect). To conclude, this study will investigate how children's advertising literacy level for these new formats can be improved by giving the children a traditional advertising literacy training session. Teaching children about advertising and the commercial purposes and techniques advertisers use, has shown to increase the level of advertising literacy. However, most of these studies are conducted in a traditional ad context. In the current study, we will investigate how a training session may increase children's advertising literacy for these new advertising formats.

\section{Conceptual Framework and Hypotheses Development}

\subsection{Defining Advergames and Advertiser Funded Programs}

AFPs are a type of branded entertainment in which the brand plays a leading role throughout the storyline of a television program. The program is entirely created and/or funded by the advertiser (Hang and Auty, 2010; Hudson and Hudson, 2006). An advergame is defined as 'a form of branded entertainment that features advertising messages, logos and trade characters in a game format' (Mallinckrodt and Mizerski, 2007, p. 87). It is a customized online game that promotes the brand of a company (Lee and Youn, 2008; Lee et al., 2009). Advergames are playful and fun, and require little skills to play (Williams and Clippinger, 2002). AFPs and advergames have a longer exposure time (compared to many other ad formats) and they are both characterized by an integration of the commercial message into the media content. The most important difference between both formats is that advergames require an active 
Children's Advertising Literacy for New Advertising Formats: The Mediating Impact of Advertising Literacy on the (Un)Intended Effects of Advergames and Advertising Funded Programs.

player and interactively engage the viewer with the content (Van Reijmersdal et al. 2012), whereas an AFP does not.

\subsection{Children's Advertising Literacy Level for Advergames versus Advertiser Funded Programs}

Cognitive advertising literacy is generally described as the skill that individuals recognize advertising, and their understanding of the persuasive intent and the techniques that are used to influence them. People may use this skill as a defense mechanism that enables them to critically process advertisements (Gunter et al., 2005; Knowles and Linn, 2004). Research has shown that advertising literacy goes hand in hand with the cognitive development of children (Piaget, 1929), implying that the younger the children are the lower their level of advertising literacy, and consumer socialization (John, 1999). Both advergames and AFPs integrate the persuasive message into a highly entertaining content. This makes it difficult for children to recognize the commercial message in both formats. However, playing an advergame requires more cognitive resources from children than watching an AFP due to the interactivity. As children's ability to process information is limited (Buijzen et al., 2010) and playing a computer game demands a lot of cognitive resources related to the interactivity of the game itself (Yuji 1996), we can expect that children's cognitive advertising literacy level is lower for an advergame than for an AFP.

H1a: Children have less cognitive advertising literacy for an advergame than for an AFP.

Playing an advergame is fundamentally different from watching an AFP based on the interactive nature of advergames (Glass, 2007; Moore, 2004; Van Reijmersdal et al., 2010). Because of this interactive nature, children are strongly involved with the game, resulting in a higher focus and the feeling of immersion in the online game (Cauberghe and De Pelsmacker, 2010; Escalas, 2004; Hsu and Lu, 2004). Although both AFPs and advergames might be very liked by children, the absortion and potential state of flow caused by the interactivity may affect children's affective advertising literacy level, that is described as their critical attitude towards the advertising format (Boerman et al., 2012; Rozendaal et al., 2012), more strongly and in a negative way (Escalas, 2004) (Privette, 1983). When playing an advergame, children's critical processing of an embedded ad is less likely, than when passively watching an AFP. 
H1b: Children have less affective advertising literacy for an advergame than for an AFP.

\subsection{Intended and Unintended Effects of Advergames versus Advertiser Funded Programs}

Research on the effectiveness of advertising distinguishes between intended and unintended effects. Intended advertising effects refer to the impact that advertising may have on brand memory, attitudes, but also, and especially with children, on purchase requests. Advertisers try to incite children to request the advertised brands with their parents. These purchase requests are also referred to as pester power. Research has shown that children who were frequently exposed to advertising, request the brands that are shown in these advertisements more often to their parents (Buijzen and Valkenburg, 2003). We expect that this pester power may be even higher for advergames than for AFPs due to children's lower level of cognitive and affective advertising literacy.

H2a: Advergames will incite a higher pester power than AFPs due to lower cognitive and affective advertising literacy.

However, next to the intended effects, advertising may also generate unintended effects with children. In this respect, previous research confirms that exposure to advertising can arouse higher materialistic values with children (Buijzen and Valkenburg, 2003; Chia, 2010). The reason for this is the fact that advertising propagates that possessions are important and that several desirable qualities (e.g., fun, hapiness, status,...) could only be obtained by acquiring material goods (Pollay, 1986; Wulfemeyer and Mueler, 1992). We expect that these unintended effects on children's materialism may be even stronger for advergames as children have lower levels of cognitive and affective advertising literacy than for AFPs.

H2b: Advergames will incite a higher materialism level than AFPs due to lower cognitive and affective advertising literacy.

\subsection{The Moderating Impact of Advertising Literacy Training Sessions}

Research has shown that children's advertising literacy level can be improved by involving them into an advertising literacy training session (e.g., Wollslager, 2009). Most of these educational packages focus on the cognitive facets of advertising literacy by teaching pupils how to recognize advertising and 
Children's Advertising Literacy for New Advertising Formats: The Mediating Impact of Advertising Literacy on the (Un)Intended Effects of Advergames and Advertising Funded Programs.

learning them to understand the persuasive intent of advertising and the techniques that advertisers use to persuade them. Teaching children about advertising and the commercial purposes and techniques advertisers use, could increase the level of advertising literacy and could eventually diminish its impact (Calvert, 2008; Eagle, 2007; Moses and Baldwin, 2005). This is in line with the 'cognitive defense view' which states that once consumers are in possession of knowledge about the persuasive intent of advertising, they become more critical about the advertiser's ulterior motives. This vision also assumes that advertising literacy could serve as a filter and a defense mechanism that reduces the susceptibility towards advertising (Gunter et al., 2005; Knowles and Linn, 2004). Nevertheless, only a few studies empirically tested the effectiveness of training sessions for new advertising formats. Wollslager (2009), for instance, found that children better recognize and identify advertising in an online context after an advertising literacy training session. Based on this research we expect that:

H3a: The advertising literacy training session will improve children's cognitive advertising literacy, regardless of the ad format.

The Reactance Theory (Brehm, 1966) predicts that people will show resistance against the persuasion attempt when they perceive that someone is trying to influence them. Based on this theory, we can also expect that:

H3b: The advertising literacy training session will improve children's affective advertising literacy, regardless of the ad format.

\section{Materials and Method}

\subsection{Design}

An experimental study using a 2 (Advertising format: AFP versus Advergame) by 2 (Course: Advertising literacy training session versus regular course) between-subjects factorial design is conducted to test the hypotheses. An advergame and an AFP were selected for the same brand, The Efteling, a famous Dutch theme park. Half of the children received a regular course (unrelated to adlit), while the other half received an advertising literacy training session before they were exposed to one of the ad formats. The study investigated 1) the level of cognitive and affective advertising literacy of children; 2) how advertising literacy mediates the effect of advertising format on pester power 
6 Hudders, Liselot; Cauberghe, Veroline; Panic, Katarina; De Vos, Wendy

and materialism and 3) whether an advertising literacy training session improves the advertising literacy of children.

\subsection{Stimulus Material}

Two existing advertisements promoting the same brand, the Dutch theme park 'Efteling', were selected. The children who were exposed to the AFP saw a television show 'De Schatkamer' that was fully built around the 'Efteling' and partly recorded in the theme park. The children who were exposed to the advergame had to play a game that was built around one of the most popular show places in the Efteling 'De sprookjesboom' (see figures 1 and 2).

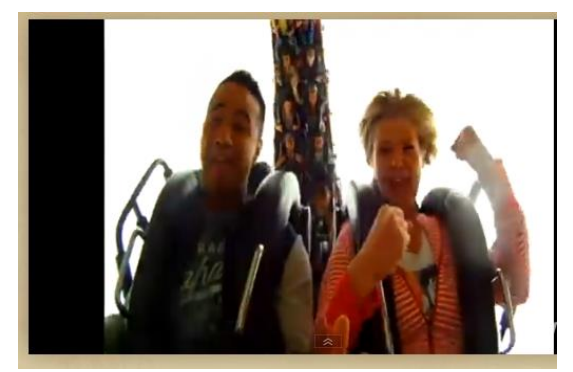

Figure 1: Efteling Advertiser Funded Program De Schatkamer

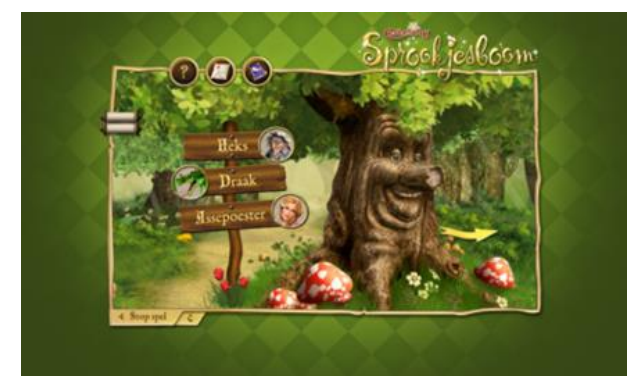

Figure 2: Efteling Advergame De Sprookjesboom

The advertising literacy training session was constructed in the form of an instructional group conversation, a commonly used method in primary schools. A PowerPoint presentation was constructed to guide the training session and all children were stimulated to actively participate in the training sessions by asking 
Children's Advertising Literacy for New Advertising Formats: The Mediating Impact of Advertising Literacy on the (Un)Intended Effects of Advergames and Advertising Funded Programs.

them questions and stimulate them to give examples. The advertising literacy training session focused on both cognitive and affective aspects of advertising literacy. The regular course was not related to advertising nor advertising literacy.

\subsection{Procedure}

First, half of the children participated in a twenty minutes advertising literacy training session while the other half participated in a twenty minutes regular course. After the children took part in this training session or course, they were either instructed to play an advergame or watch an AFP, both for three minutes (to obtain uniform exposure time). Afterwards, children were asked to complete a short questionnaire to measure their advertising literacy level, advertising effectiveness and socio-demographics.

\subsection{Participants}

Children between the age of seven and nine from two different elementary schools in a Western European country were recruited to participate in this study. Only children whose parents provided consent, participated in the study. In total, 133 seven- to nine-year-old children $(54.9 \%$ boys, Mage $=7.95)$ participated in this study.

\subsection{Measurement instrument}

The questionnaire was adapted to the age of the children (e.g., response categories took the form of smileys; Mallinckrodt and Mizerski, 2007). First, advertising literacy was measured. To measure cognitive advertising literacy an existing three-item scale was used following Van Reijmersdal et al. (2012) ('Who do you think put De Efteling in the game/fragment? The teacher, the producer, De Efteling, ...'; 'Why do they show De Efteling in this game/fragment? To like the game/program, to like De Efteling, to make me happy, ...'; 'Does the game/fragment want you to go to De Efteling? Yes, no'). The correct answers were summated.

To measure affective advertising literacy, the item 'How much do you like playing such games/watching such program's?' was used, answered on a fivepoint likert scale.

To measure pester power the item 'Will you ask your parents to go to the Efteling?' was used, answered on a five-point likert scale (Buijzen, 2007). 
8 Hudders, Liselot; Cauberghe, Veroline; Panic, Katarina; De Vos, Wendy

Finally, materialism was measured using a shortened three-item version of the Material Value Scale for Children (Opree et al., 2011) (e.g. 'Do you think it is important to have expensive things?'; 'Does buying expensive things make you happy?')

\section{Results}

To test hypothesis one $\mathrm{a}$ and $\mathrm{b}$, two independent $\mathrm{T}$-tests are performed using the advertising format (AFP versus advergame) as independent variable and the cognitive and affective advertising literacy level as dependent variables.

The results do not confirm H1a as children's cognitive advertising literacy level does not differ for the AFP $(\mathrm{M}=.62, \mathrm{SE}=.04)$ versus the advergame $(\mathrm{M}=$ $.63, \mathrm{SE}=.04 ;(\mathrm{t}(130)=-.31, \mathrm{p}=.76)$.

However, hypothesis $1 \mathrm{~b}$ is supported in that children have a higher level of affective advertising literacy for the AFP $(\mathrm{M}=3.40, \mathrm{SE}=.14)$ than for the advergame $(\mathrm{M}=4.10, \mathrm{SE}=.14 ;(\mathrm{t}(131)=3.36, \mathrm{p}=.001)$. Children are thus more critical and skeptical towards the AFP than towards advergames.

\section{Cognitive Advertising Literacy}

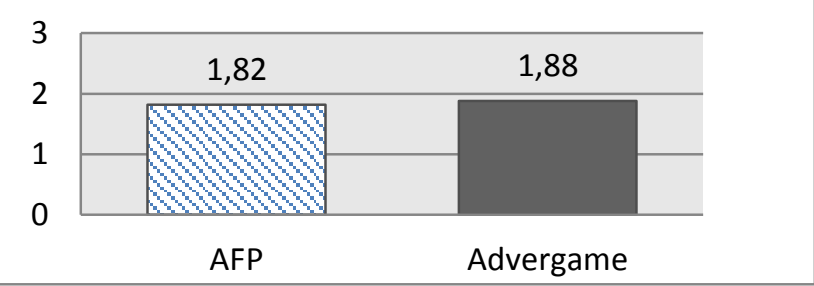

Figure 3: The Impact of Ad Format on Cognitive Advertising Literacy 
Children's Advertising Literacy for New Advertising Formats: The Mediating Impact of Advertising Literacy on the (Un)Intended Effects of Advergames and Advertising Funded Programs.

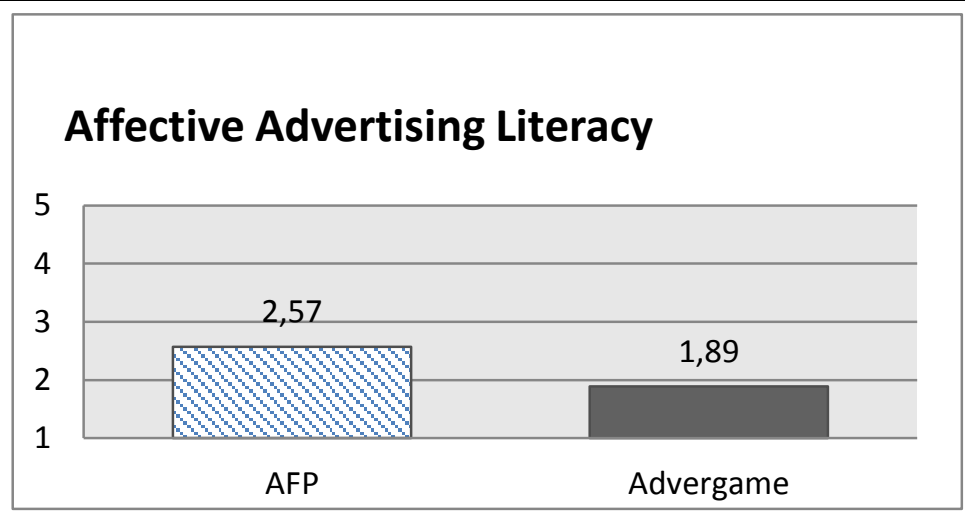

Figure 4: The Impact of Ad Format on Affective Advertising Literacy

To test hypothesis two, a multiple mediation analysis is conducted to test the mediating effect of cognitive and affective advertising literacy on pester power and materialism (Hayes, 2013; PROCESS, model 4, 5000 bootstrap resamples). This analysis shows that the affective advertising literacy significantly mediates $(\mathrm{B}=.2953, \mathrm{SE}=.1097,95 \% \mathrm{CI}=[.1197, .5562])$ the effect of advertising format on purchase request, but cognitive advertising literacy does not $(\mathrm{B}=$ $.0178, \mathrm{SE}=.0596,95 \% \mathrm{CI}=[-.0965, .1473])$. The same results were found for materialism. Affective advertising literacy mediates $(\mathrm{B}=.0281, \mathrm{SE}=.0164$, $95 \% \mathrm{CI}=[.0038, .0704])$ the impact of advertising format on materialism, but cognitive advertising literacy does not $(\mathrm{B}=-.0003, \mathrm{SE}=.0052,95 \% \mathrm{CI}=[-$ $.0140, .0087])$. Hypothesis two is thus only partly confirmed in that only affective advertising literacy mediates the effects of format on pester power and materialism and cognitive advertising literacy does not.

Hypothesis three was tested using a two-factor multivariate analysis of variance (MANOVA) with the advertising literacy training session and the advertising format as independent variables and cognitive and affective advertising literacy as dependent variables. The results show a significant main effect of advertising literacy training session on cognitive $(F(1,131)=20.32$, p $<.001)$ and affective advertising literacy $(\mathrm{F}(1,132)=14.61, \mathrm{p}<.001)$ confirming hypothesis three $\mathrm{a}$ and $\mathrm{b}$. Children who took part in the training session $(\mathrm{M}=.74, \mathrm{SE}=.04)$ showed a higher level of cognitive advertising literacy compared to children who received a regular course $(\mathrm{M}=.51, \mathrm{SE}=.04)$. Also children who received the training session $(\mathrm{M}=3.40, \mathrm{SE}=.14)$ showed a higher level of affective advertising literacy than children who did not receive the training session $(\mathrm{M}=4.10, \mathrm{SE}=.13)$. Both for cognitive $(\mathrm{F}(1,131)=.32, \mathrm{p}$ 
$>.05)$ and affective advertising literacy $(\mathrm{F}(1,132)=.05, \mathrm{p}=.83)$ there are no significant interaction effects of the format and the training session

\section{Discussion and Conclusion}

The results show that the effect of the two tested advertising formats on (7to-9-year old) children's advertising literacy is significantly different. Advergames evoked a lower level of affective advertising literacy than AFPs. However, they do not ensure a lower level of cognitive advertising literacy. This means that while children are more critical towards an AFP, they have no better understanding of the persuasive intent of an AFP in comparison to an advergame. A possible explanation is that because both advertising formats integrate the commercial message into the media content, a ceiling effect is reached concerning the difficulty of understanding the persuasive intent of these formats. However, the level of interactivity, which is the main difference between both formats, seems to relate more to the affective component of persuasion knowledge because of the feelings of fun and escapism with which it is associated (Escalas, 2004). Also, the results show that the impact of advertising format on pester power and materialism is mediated by affective persuasion knowledge, but not by cognitive persuasion knowledge. This is in line with previous research (e.g. Hudders et al., 2014).

When children followed an advertising literacy training session before the exposure of an advergame or AFP, they reported higher levels of cognitive and affective advertising literacy. This is in line with the Reactance Theory of Brehm (1966) that states that children become more critical towards advertising when they perceive a persuasion attempt.

The limitations of the current study provide directions for further research. Further research should work with fictitious and unknown brands to avoid previously formed brand attitudes. Also, to efficiently examine the differences of advertising effectiveness, a comparison should be made of a service and a product, while the present study only focuses on a service (cf. the theme parc). In addition, there was only a single exposure to the advertising format in an unnatural setting. It is recommended to investigate the effects of these formats after repeated exposure to the stimuli.

\section{References}

Boerman, S. C.; Van Reijmersdal, E. A. and Neijens, P. C. (2012), "Sponsorship disclosure: effects of duration on persuasion knowledge and brand responses," in: Journal of Communication, 62 (6), 1047-1064. 
Children's Advertising Literacy for New Advertising Formats: The Mediating Impact of Advertising Literacy on the (Un)Intended Effects of Advergames and Advertising Funded Programs.

Bottelberghs, I. (2007), "Consumensjes: over kinderen, reclame en communicatie," Leuven, Uitgeverij LannooCampus.

Brehm, J. (1966), "A theory of psychological reactance, " New York, Academic Press.

Buijzen, M. (2007), "Reducing children's susceptibility to commercials: mechanisms of factual and evaluative advertising interventions, " in: Media Psychology, 9 (2), 411-430.

Buijzen, M. and Valkenburg, P. M. (2003), "The unintended effects of television advertising: a parent-child survey, " in: Communication Research, 30 (5), 483-503.

Buijzen, M.; Van Reijmersdal, E. A. and Owen, L. H. (2010), "Introducing the PCMC model: an investigative framework for young people's processing of commercialized media content, " in: Communication Theory, 20 (4), 427-450.

Calvert, S. L. (2008), "Children as consumers: advertising and marketing, " in: The Future of Children, 18 (1), 205-234.

Campbell, M. C. and Kirmani, A. (2000), "Consumers' use of persuasion knowledge: the effects of accessibility and cognitive capacity on perceptions of an influence agent, " in: Journal of Consumer Research, 27 (1), 69-83.

Cauberghe, V. and De Pelsmacker, P. (2010), "Advergames: the impact of brand prominence and game repetition on brand responses, " in: Journal of Advertising, 39 (1), 5-18.

Chia, C. S. (2010), "How social influence mediates media effects on adolescents' materialism, " in: Communication Research, 37 (3), 400-419.

Eagle, L. (2007), "Commercial media literacy: what does it do, to whom and does it matter?, " in: Journal of Advertising, 36 (2), 101-110.

Escalas, J. E. (2004), "Imagine yourself in the product: mental simulation, narrative transportation, and persuasion, " in: Journal of Advertising, 33 (2), 37 48.

Glass, Z. (2007), "The effectiveness of product placement in video games, " in: Journal of Interactive Advertising, 8 (1), 23-32.

Gunter, B.; Oates, C. and Blades, M. (2005), "Adversing to children on TV: content, impact and Regulation, " New Jersey, Lawrence Erlbaum Associations.

Hang, H. and Auty, S. (2011), "Children playing branded video games: the impact of interactivity on product placement effectiveness," in: Journal of Consumer Psychology, 21 (1), 65-72.

Hsu, C. and Lu, H. (2004), "Why do people play on-line games? An extended TAM with social influences and flow experience," in: Information \& Management, 41 (7), 853-868.

Hudders, L., Cauberghe, V. and Panic, K. (2014), "Advertising Literacy in an Advergame Context. The Moderating Impact of an Advertising Literacy 
Training Session on Children's Advertising Vulnerability," Paper presented at the 43rd European Marketing Academy, Valencia, Spain, June 2014.

Hudson, S. and Hudson, D. (2006), "Branded entertainment: a new advertising technique or product placement in disguise?, " in: Journal of Marketing Management, 22 (5/6), 489 - 504.

John, D. R. (1999), "Consumer socialization of children: a retrospective look at twenty-five years of research, " in: Journal of Consumer Research, 26 (3), 183-213.

Knowles, E. and Linn, J. (2004), "Resistance and persuasion, " Mahwah, NJ, Erlbaum.

Lee, M.; Choi, Y.; Quilliam, E. T. and Cole, R. T. (2009), "Playing with food: content analysis of food advergames, " in: Journal of Consumer Affairs, 43 (1), 129-154.

Lee, M. and Youn, S. (2008), "Leading national advertisers' uses of advergames, " in: Journal of Current Issues and Research in Advertising, 30 (2) $1-13$.

Mallinckrodt, V. and Mizerski, D. (2007), "The effects of playing an advergame on young children's perceptions, preferences, and requests, " in: Journal of Advertising, 36 (2), 87-100.

Moore, E. S. (2004), "Children and the changing world of advertising," in: Journal of Business Ethics, 52 (2), 161-167.

Moses, L. J. and Baldwin, D. A. (2005), "What can the study of cognitive development reveal about children's ability to appreciate and cope with advertising?, " in: American Marketing Association, 24 (2), 186-201.

Nicholls, A. J. and Cullen, P. (2004), "The child-parent relationship: 'pester power', human rights and retail ethics," in: Journal of Retailing and Consumer Services, 11 (2), 75-86.

Opree, S. J.; Buijzen, M.; van Reijmersdal, E. A. and Valkenburg, P. M. (2011), "Development and validation of the Material Values Scale for children (MVS-c), " in: Personality and Individual Differences, 51 (8), 963-968.

Panic, K.; Cauberghe, V. and De Pelsmacker, P. (2013), "Comparing TV ads and advergames targeting children: the impact of persuasion knowledge on behavioural response," Journal of Advertising, 42 (2/3), 264-273.

Piaget, J. (1929), "The child's conception of the world," New York, Hartcourt, Brace \& Co.

Pollay, R. W. (1986), "The distorted mirror - reflections on the unintended consequences of Advertising," in: Journal of Marketing, 50 (2), 18-36.

Privette, G. (1983), "Peak experience, peak performance, and flow - a comparative-analysis of positive human experiences," in: Journal of Personality and Social Psychology, 45 (6), 1361-1368. 
Children's Advertising Literacy for New Advertising Formats: The Mediating Impact of Advertising Literacy on the (Un)Intended Effects of Advergames and Advertising Funded Programs.

Rozendaal, E.; Buijzen, M. and Valkenburg, P. M. (2011), "Children's understanding of advertisers' persuasive tactics, " in: International Journal of Advertising, 30 (2), 329-350.

Rozendaal, E.; Buijzen, M. and Valkenburg, P. M. (2012), "Think-aloud process superior to thought-listing in increasing children's critical processing of advertising," Human Communication Research, 38 (2), 199-221.

Van Reijmersdal, E. A.; Jansz, J.; Peters, O. and van Noort, G. (2010), "The effects of interactive brand placements in online games on children's cognitive, affective and conative brand responses, " in: Computers in Human Behavior, 26 (6), 1787-1794.

Van Reijmersdal, E. A.; Rozendaal, E. and Buijzen, M. (2012), "Effects of prominence, involvement, and persuasion knowledge on children's cognitive and affective responses to advergames," in: Journal of Interactive Marketing, 26 (1), $33-42$.

Williams, R. B. and Clippinger, C. A. (2002), "Aggression, competition and computer games: computer and human opponents, " in: Computers in Human Behavior, 18 (5), 495-506.

Wollslager, M. E. (2009), "Children's awareness of online advertising on neopets: the effect of media literacy training on recall," in: Studies in Media and Information Literacy Education, 9 (2), 31-53.

Wulfemeyer, K. T. and Mueller, B. (1992), "Channel One and commercials in classrooms: Advertising content aimed at students," in: Journalism Quarterly, 69 (3), 724-742.

Yuji, H. (1996), "Computer games and information-processing skills," in: Perceptual and Motor Skills, 83 (2), 643-647. 